\title{
HIV/HCV Antiviral Drug Interactions in the Era of Direct-acting Antivirals
}

\author{
Donald P. Rice Jr.*1, John J. Faragon ${ }^{2}$, Sarah Banks ${ }^{3}$ and Lisa M. Chirch ${ }^{1}$ \\ ${ }^{1}$ Division of Infectious Diseases, Department of Medicine, University of Connecticut School of Medicine, Farmington, CT, USA; \\ ${ }^{2}$ Division of HIV Medicine, Albany Medical Center, Albany, NY, USA; ${ }^{3}$ Department of Medicine, The Hospital of Central Connecticut, \\ University of Connecticut School of Medicine, Farmington, CT, USA
}

\begin{abstract}
Therapy for human immunodeficiency virus (HIV) and chronic hepatitis $C$ has evolved over the past decade, resulting in better control of infection and clinical outcomes; however, drug-drug interactions remain a significant hazard. Joint recommendations from the American Association for the Study of Liver Diseases and the Infectious Diseases Society of America regarding drug-drug interactions between HIV antiretroviral agents and direct-acting antiviral agents for treatment of hepatitis $\mathrm{C}$ virus ( $\mathrm{HCV}$ ) infection are reviewed here. This review is oriented to facilitate appropriate selection of an antiviral therapy regimen for $\mathrm{HCV}$ infection based on the choice of antiretroviral therapy being administered and, if necessary, switching antiretroviral regimens.

(C) 2016 The Second Affiliated Hospital of Chongqing Medical University. Published by XIA \& HE Publishing Inc. All rights reserved.
\end{abstract}

\section{Introduction}

Therapy for human immunodeficiency virus (HIV) and hepatitis $\mathrm{C}$ virus (HCV) infections has evolved significantly over the past decade, resulting in far better control of infection and clinical outcomes. Patients with chronic HCV who are coinfected with HIV are more likely to suffer liver-related complications, and therefore represent a high priority target population to receive treatment with newer direct-acting antiviral agents. ${ }^{1,2}$ These newer agents are well tolerated and result in excellent cure rates, including in the HIV-infected patient population. Drug-drug interactions, however, remain a significant obstacle to effective therapy, and an awareness of such interactions and how to avoid and manage them is imperative upon embarking on therapy for the coinfected patient. The aim of this review is to facilitate selection of

Keywords: HIV; Hepatitis C; Direct-acting antivirals; Drug interactions; Pharmacokinetics; Antiretroviral therapy.

Abbreviations: HIV, human immunodeficiency virus; $\mathrm{HCV}$, hepatitis $\mathrm{C}$ virus; $\mathrm{PI}$ : protease inhibitor; AUC, area under the curve; NS, non-structural protein; DHHS, United States Department of Health and Human Services.

Received: 11 July 2016; Revised: 03 September 2016; Accepted: 17 September 2016

DOI: $10.14218 / \mathrm{JCTH} .2016 .00026$.

* Correspondence to: Donald P. Rice, Jr., Division of Infectious Diseases, Department of Medicine, University of Connecticut School of Medicine, 263 Farmington Ave., Farmington, CT 06030, USA. Tel: +1-757-561-8323, Fax: +1-860-679-4701, E-mail: drice@uchc.edu, donnyrice@gmail.com an appropriate regimen for HCV therapy based on existing comorbidities and antiretroviral therapy.

\section{Background}

Recent estimates indicate more than 150 million people are infected with HCV globally, with nearly 4 million in the United States, representing a primary etiology of end-stage liver disease and indication for liver transplantation. ${ }^{3}$ Approximately one-third of the HCV infected population is also HIV infected, a population at risk for more rapid progression to advanced liver disease and cirrhosis, and associated morbidity and mortality. ${ }^{4}$

While the advent of new agents for the treatment of both infections have greatly simplified regimens and improved tolerability and outcomes for this population, these outcomes may be compromised by drug-drug interactions. Certain antiretroviral classes are more likely to interact with various direct-acting antivirals by virtue of their specific metabolism and pharmacokinetics, and antiretroviral regimen switches are often necessary to accommodate therapy with directacting antivirals. Recognizing patients' antiretroviral history, including intolerances, virologic failures, and resultant viral resistance mutations is critical to successful transition once a direct-acting antiviral regimen has been chosen. New testing modalities, such as next-generation sequencing (GenoSure Archive ${ }^{\circledR}$ ) can be performed despite undetectable HIV ribonucleic acid levels to identify potential archived mutations. ${ }^{5}$ This allows for safer, more reliable antiretroviral switches in patients well controlled on their current regimen.

Drug-drug interactions can be complex and often mandate switches in antiretroviral regimens, temporary or permanent, with close clinical monitoring to ensure both infections are adequately addressed and controlled. ${ }^{4}$ Successful treatment of chronic $\mathrm{HCV}$, evidenced by sustained virologic response at 12 weeks post-completion, has been associated with a significant reduction in morbidity and mortality related to hepatic complications. ${ }^{6}$ Given the disproportionate long-term effects on the coinfected population, the ability to adequately evaluate and maneuver antiretroviral and antiviral drug-drug interactions is paramount to successful management of these infections.

\section{Pharmacology}

The direct-acting antiviral regimens currently available can be split up into 6 broad regimens. While each may play an important role in the management of different HCV genotypes, the use of antiviral agents for HCV is likely to 
lead to drug interactions, especially when combined with antiretroviral therapy.

In general, medications used in HCV therapy can be affected by or can affect HIV antiretroviral therapy in one of two ways - by affecting their metabolism or their absorption. Metabolism interactions are more common since many of the $\mathrm{HCV}$ and HIV medications are either substrates, inhibitors or inducers of either the cytochrome P-450 enzyme system or other transporter systems, such as those involving the permeability glycoprotein, breast cancer resistance protein, or the organic anion transporting polypeptide $1 \mathrm{~B} 1$ and $1 \mathrm{~B} 3$ transporters. When combining HIV and HCV medications, the result is usually one or a combination of three consequences: first, the HCV medication levels are dramatically increased, leading to toxicity (i.e. grazoprevir levels increase when combined with boosted HIV protease inhibitors (PIs), leading to potential hepatotoxicity) ${ }^{7}$ second, the HCV medication leads to an increase in HIV medication drug levels (i.e. paritaprevir, ritonavir, ombitasvir and dasabuvir combination therapy increasing rilpivirine levels, leading to potential Q-T interval prolongation $)^{8}$ or third, the levels of the HCV medications are reduced, risking $\mathrm{HCV}$ treatment failure (i.e. efavirenz reducing the drug levels of velpatasvir $)^{9}$ through induction.

Direct-acting antiviral agents generally do not lower levels of antiretroviral agents as none induce hepatic enzymes; however, decreased darunavir levels have been demonstra- ted in patients taking paritaprevir, ritonavir, ombitasvir and dasabuvir combination therapy. ${ }^{10}$ Since each of these results is likely to impact either HIV or HCV treatment outcomes, providers should be aware of how regimens used in HCV are metabolized, and more importantly, use regimens for both HIV and HCV that will optimize patient outcomes with minimal adverse events. Table 1 summarizes HCV therapeutic options, mechanisms of action and metabolism, including the effect of HCV regimens on cytochrome P-450 enzymes, permeability glycoprotein, breast cancer resistance protein, or organic anion transporting polypeptide transport systems.

\section{Interactions by antiretroviral class}

\section{Nucleoside reverse transcriptase inhibitors}

Nucleoside reverse transcriptase inhibitors are used in all currently recommended antiretroviral regimens. Tables 2, 3 and 4 summarize the guideline-recommended antiretroviral regimens and the clinically important drug-drug interactions by individual antiretroviral agent and regimen, respectively.

Tenofovir is a nucleoside reverse transcriptase inhibitor used extensively in treatment of HIV and is associated with several forms of toxicity which can be exacerbated by coadministration with HCV therapies. Ledipasvir has been shown to increase tenofovir levels and potentiate the risk of

Table 1. Hepatitis C antiviral drug metabolism ${ }^{29-33}$

\begin{tabular}{|c|c|c|c|c|c|}
\hline & $\begin{array}{l}\text { Hepatitis C virus site } \\
\text { of action }\end{array}$ & $\begin{array}{l}\text { Cytochrome } \\
\text { P- } 450\end{array}$ & $\begin{array}{l}\text { Permeability } \\
\text { glycoprotein }\end{array}$ & $\begin{array}{l}\text { Breast cancer } \\
\text { resistance protein }\end{array}$ & $\begin{array}{l}\text { Organic anion-transporting } \\
\text { polypeptide }\end{array}$ \\
\hline Sofosbuvir & NS5b polymerase & No effect & Substrate & Substrate & No effect \\
\hline Daclatasvir & NS5a polymerase & Substrate & Inhibitor & Inhibitor & $1 \mathrm{~B} 1$ and $1 \mathrm{~B} 3$ inhibitor \\
\hline Grazoprevir & NS3/4a protease & Substrate & Substrate & No effect & Substrate \\
\hline Elbasvir & NS5a polymerase & Substrate & Substrate & No effect & No effect \\
\hline Ledipasvir & NS5a polymerase & No effect & Inhibitor & Inhibitor & No effect \\
\hline $\begin{array}{l}\text { Paritaprevir, } \\
\text { Ritonavir, } \\
\text { Ombitasvir, } \\
\text { Dasabuvir }\end{array}$ & $\begin{array}{l}\text { NS3/4a serine } \\
\text { protease, } \\
\text { pharmacokinetic } \\
\text { enhancer, NS5a } \\
\text { protease, NS5b } \\
\text { polymerase }\end{array}$ & $\begin{array}{l}\text { Paritaprevir, } \\
\text { Ritonavir } \\
\text { (inhibitors) }\end{array}$ & $\begin{array}{l}\text { Ritonavir } \\
\text { (inhibitor) }\end{array}$ & No effect & No effect \\
\hline Simeprevir & NS3/4a protease & $\begin{array}{l}\text { Inhibitor, } \\
\text { intestinal }\end{array}$ & Inhibitor & No effect & Inhibitor \\
\hline Velpatasvir & NS5a polymerase & No effect & Inhibitor & Inhibitor & Inhibitor \\
\hline
\end{tabular}

NS, denotes non-structural protein.

Table 2. Preferred initial antiretroviral regimens ${ }^{34}$

Integrase strand transfer inhibitor-based

Protease inhibitor-based dolutegravir/abacavir/lamivudine*

dolutegravir + tenofovir disoproxil fumarate/emtricitabine elvitegravir/cobicistat/tenofovir disoproxil fumarate/ emtricitabine**

elvitegravir/cobicistat/tenofovir alafenamide/emtricitabine ${ }^{* * *}$ raltegravir + tenofovir disoproxil fumarate/emtricitabine darunavir/ritonavir + tenofovir disoproxil fumarate/emtricitabine

\footnotetext{
* Only if Human Leukocyte Antigen B*5701-negative.

** Only if pre-treatment creatinine clearance is above $70 \mathrm{~mL} / \mathrm{min}$.

Only if pre-treatment creatinine clearance is greater than $30 \mathrm{~mL} / \mathrm{min}$.
} 
Table 3. Summary of direct-acting antiviral and antiretroviral drug compatibility ${ }^{29-33}$

\begin{tabular}{|c|c|c|c|c|c|c|}
\hline $\begin{array}{l}\text { Nucleoside } \\
\text { Reverse } \\
\text { Transcriptase } \\
\text { Inhibitors }\end{array}$ & $\begin{array}{l}\text { Daclatasvir/ } \\
\text { Sofosbuvir* }\end{array}$ & $\begin{array}{l}\text { Grazoprevir/ } \\
\text { Elbasvir }\end{array}$ & $\begin{array}{l}\text { Ledipasvir/ } \\
\text { Sofosbuvir }\end{array}$ & $\begin{array}{l}\text { Paritaprevir/Ritonavir/ } \\
\text { Ombitasvir/Dasabuvir }\end{array}$ & $\begin{array}{l}\text { Simeprevir/ } \\
\text { Sofosbuvir }\end{array}$ & $\begin{array}{l}\text { Velpatasvir/ } \\
\text { Sofosbuvir }\end{array}$ \\
\hline Abacavir & $Y$ & $\mathrm{Y}$ & $Y$ & $Y$ & $\mathrm{Y}$ & $Y$ \\
\hline Didanosine & $Y$ & $Y$ & $Y$ & Y & $Y$ & $Y$ \\
\hline Emtricitabine & Y & Y & Y & Y & Y & Y \\
\hline Lamivudine & Y & $Y$ & $Y$ & Y & $Y$ & $Y$ \\
\hline Stavudine & $Y$ & $Y$ & $Y$ & Y & $Y$ & $Y$ \\
\hline $\begin{array}{l}\text { Tenofovir } \\
\text { disoproxil } \\
\text { fumarate }\end{array}$ & $Y$ & $Y$ & $\mathrm{Y}^{* *}$ & Y & $Y$ & $\mathrm{Y}^{* *}$ \\
\hline $\begin{array}{l}\text { Tenofovir } \\
\text { alafenamide }\end{array}$ & $Y$ & $\mathrm{Y}$ & $\mathrm{Y}$ & $\mathrm{Y}$ & $\mathrm{Y}$ & $Y$ \\
\hline Zidovudine & Y & $\mathrm{Y}$ & $\mathrm{Y}$ & Y & $\mathrm{Y}$ & $\mathrm{Y}$ \\
\hline \multicolumn{7}{|c|}{ Non-nucleoside reverse transcriptase inhibitors } \\
\hline Efavirenz & $\begin{array}{l}\text { Y, daclatasvir } \\
90 \mathrm{mg}\end{array}$ & $\mathrm{N}$ & Y & $\mathrm{N}$ & $\mathrm{N}$ & $\mathrm{N}$ \\
\hline Etravirine & $\begin{array}{l}\text { Y, daclatasvir } \\
90 \mathrm{mg}\end{array}$ & $\mathrm{N}$ & $\mathrm{Y}$ & $\mathrm{N}$ & $\mathrm{N}$ & Y \\
\hline Nevirapine & $\begin{array}{l}\text { Y, daclatasvir } \\
90 \mathrm{mg}\end{array}$ & $\mathrm{N}$ & Y & $\mathrm{N}$ & $\mathrm{N}$ & Y \\
\hline Rilpivirine & Y & Y & Y & $\mathrm{N}$ & $\mathrm{Y}$ & $\mathrm{Y}$ \\
\hline \multicolumn{7}{|c|}{ Protease inhibitors } \\
\hline $\begin{array}{l}\text { Atazanavir, } \\
\text { unboosted }\end{array}$ & Y & $\mathrm{N}$ & Y & Y & $\mathrm{N}$ & Y \\
\hline $\begin{array}{l}\text { Atazanavir/ } \\
\text { cobicistat }\end{array}$ & $\begin{array}{l}\text { Y, daclatasvir } \\
30 \mathrm{mg}\end{array}$ & $\mathrm{N}$ & $\mathrm{Y}$ & $U$ & $\mathrm{~N}$ & $\mathrm{Y}$ \\
\hline $\begin{array}{l}\text { Atazanavir/ } \\
\text { ritonavir }\end{array}$ & $\begin{array}{l}\text { Y, daclatasvir } \\
30 \mathrm{mg}\end{array}$ & $\mathrm{N}$ & $\mathrm{Y}$ & Y & $\mathrm{N}$ & Y \\
\hline $\begin{array}{l}\text { Darunavir/ } \\
\text { cobicistat }\end{array}$ & Y & $\mathrm{N}$ & Y & $\mathrm{N}$ & $\mathrm{N}$ & Y \\
\hline $\begin{array}{l}\text { Darunavir/ } \\
\text { ritonavir }\end{array}$ & $\mathrm{Y}$ & $\mathrm{N}$ & Y & $\mathrm{N}$ & $\mathrm{N}$ & $\mathrm{Y}$ \\
\hline $\begin{array}{l}\text { Fosamprenavir, } \\
\text { unboosted }\end{array}$ & $\mathrm{Y}$ & $\mathrm{N}$ & Y & $\mathrm{N}$ & $\mathrm{N}$ & $\mathrm{Y}$ \\
\hline $\begin{array}{l}\text { Fosamprenavir/ } \\
\text { ritonavir }\end{array}$ & $U$ & $\mathrm{~N}$ & Y & $\mathrm{N}$ & $\mathrm{N}$ & $\mathrm{Y}$ \\
\hline $\begin{array}{l}\text { Lopinavir/ } \\
\text { ritonavir }\end{array}$ & $\mathrm{Y}$ & $\mathrm{N}$ & $\mathrm{Y}$ & $\mathrm{N}$ & $\mathrm{N}$ & $\mathrm{Y}$ \\
\hline $\begin{array}{l}\text { Tipranavir/ } \\
\text { ritonavir }\end{array}$ & $U$ & $\mathrm{~N}$ & $\mathrm{~N}$ & $\mathrm{~N}$ & $\mathrm{~N}$ & $\mathrm{~N}$ \\
\hline \multicolumn{7}{|c|}{ Integrase strand transfer inhibitors } \\
\hline Dolutegravir & $\mathrm{Y}$ & $Y$ & $Y$ & $Y$ & $\mathrm{Y}$ & $Y$ \\
\hline $\begin{array}{l}\text { Elvitegravir/ } \\
\text { cobicistat/ } \\
\text { tenofovir } \\
\text { alafenamide/ } \\
\text { emtricitabine }\end{array}$ & $Y$ & $\mathrm{~N}$ & $Y$ & $\mathrm{~N}$ & $\mathrm{~N}$ & $Y$ \\
\hline
\end{tabular}


Table 3. (continued)

\begin{tabular}{|c|c|c|c|c|c|c|}
\hline $\begin{array}{l}\text { Nucleoside } \\
\text { Reverse } \\
\text { Transcriptase } \\
\text { Inhibitors }\end{array}$ & $\begin{array}{l}\text { Daclatasvir/ } \\
\text { Sofosbuvir* }\end{array}$ & $\begin{array}{l}\text { Grazoprevir/ } \\
\text { Elbasvir }\end{array}$ & $\begin{array}{l}\text { Ledipasvir/ } \\
\text { Sofosbuvir }\end{array}$ & $\begin{array}{l}\text { Paritaprevir/Ritonavir/ } \\
\text { Ombitasvir/Dasabuvir }\end{array}$ & $\begin{array}{l}\text { Simeprevir/ } \\
\text { Sofosbuvir }\end{array}$ & $\begin{array}{l}\text { Velpatasvir/ } \\
\text { Sofosbuvir }\end{array}$ \\
\hline $\begin{array}{l}\text { Elvitegravir/ } \\
\text { cobicistat/ } \\
\text { tenofovir } \\
\text { disoproxil } \\
\text { fumarate/ } \\
\text { emtricitabine }\end{array}$ & $\begin{array}{l}\text { Y, daclatasvir } \\
30 \mathrm{mg}\end{array}$ & $\mathrm{N}$ & $\mathrm{N}$ & $\mathrm{N}$ & $\mathrm{N}$ & Y \\
\hline Raltegravir & $\mathrm{Y}$ & Y & Y & $\mathrm{Y}$ & Y & Y \\
\hline \multicolumn{7}{|c|}{ Entry inhibitors } \\
\hline Maraviroc & Y & $\mathrm{N}$ & Y & $\mathrm{N}$ & Y & Y \\
\hline
\end{tabular}

Y: Use at normal doses appropriate, N: Do not use concurrently, U: Unknown implication of interactions, avoid if possible.

** Daclatasvir dose is $60 \mathrm{mg}$, unless otherwise noted, when able to be combined.

** When using protease inhibitors (with or without ritonavir) or efavirenz with tenofovir disoproxil fumarate, potential increases in tenofovir levels may occur, monitor for decreased renal function. Interaction not described with tenofovir alafenamide formulations.

tenofovir-mediated nephrotoxicity. This is primarily a concern for preparations of tenofovir disoproxil fumarate. Tenofovir levels are increased in the setting of renal failure (creatinine clearance less than 60), when taken with elvitegravir and cobicistat, and are highest with ritonavir use, such as with ritonavir-boosted HIV PIs. ${ }^{1}$ Increased tenofovir exposure is also seen when ledipasvir/sofosbuvir is administered with tenofovir disoproxil fumarate along with dolutegravir, efavirenz, rilpivirine and ritonavir-boosted atazanavir or darunavir. ${ }^{11,12}$ That said, interactions with rilpivirine and dolutegravir are not likely to be clinically meaningful, and no dose adjustments are recommended. ${ }^{1}$ Close monitoring of creatinine clearance is indicated when ledipasvir/sofosbuvir is coadministered with tenofovir disoproxil fumarate and efavirenz or a ritonavir-boosted PI. Consideration of antiretroviral regimen switches to eliminate tenofovir disoproxil fumarate (utilizing abacavir or tenofovir alafenamide), ${ }^{13}$ efavirenz or ritonavirboosted PIs is also reasonable in consultation with an HIV expert (utilizing raltegravir, dolutegravir or rilpivirine, for example). Tenofovir alafenamide results in reduced serum tenofovir levels and has decreased toxicity.

Given the information available, chronic hepatitis $C$ and HIV coinfected patients on tenofovir disoproxil fumarate and a ritonavir-boosted HIV PI should only be given ledipasvir/ sofosbuvir if the need for treatment of HCV is urgent and the risks of switching antiretroviral agents are also high. Of note, no significant drug-drug interactions have been noted between tenofovir disoproxil fumarate or tenofovir alafenamide and daclatasvir, ${ }^{14}$ simeprevir, sofosbuvir, ${ }^{15}$ elbasvir/grazoprevir, ${ }^{16}$ or paritaprevir, ritonavir, ombitasvir, and dasabuvir combination therapy. ${ }^{17}$

Due to similar mechanisms of action, the combination of ribavirin with didanosine or stavudine has the potential to cause severe mitochondrial toxicity, leading to lactic acidosis, pancreatitis and hepatic steatosis. Therefore, these combinations should be avoided. ${ }^{18}$ While ribavirin can cause dose-related hemolytic anemia, zidovudine may in turn exacerbate anemia by inhibiting hematopoiesis and bone marrow response. Coadministration of zidovudine as part of an antiretroviral regimen with ribavirin is therefore contraindicated. ${ }^{19}$
Other nucleoside reverse transcriptase inhibitors used in first-line antiretroviral regimens, specifically lamivudine, emtricitabine and abacavir, are not expected to have clinically important drug-drug interactions when utilized with newer direct-acting antiviral agents.

\section{Non-nucleoside reverse transcriptase inhibitors}

Of the non-nucleoside reverse transcriptase inhibitors, efavirenz is the most potent inducer of cytochrome P-450 3A4, and therefore has the greatest potential for adverse drug interactions with other substrates, generally resulting in reduced substrate concentrations. This is true of simeprevir, paritaprevir, grazoprevir (given as a coformulation with elbasvir) and daclatasvir. ${ }^{20}$ The dose of daclatasvir, however, can be increased to $90 \mathrm{mg}$ when coadministered with efavirenz to offset this effect. ${ }^{13,20}$ Efavirenz should not be coadministered with the HCV PIs simeprevir, paritaprevir or grazoprevir. No significant interaction has been identified between efavirenz and sofosbuvir. When sofosbuvir is coformulated with ledipasvir and the antiretroviral regimen also contains tenofovir disoproxil fumarate, careful monitoring of renal function is indicated due to increased tenofovir exposure secondary to likely inhibition of the permeability glycoprotein- and breast cancer resistance protein-mediated tenofovir efflux by ledipasvir, as discussed above. ${ }^{13}$ Based on this, some experts recommend a priori switches to minimize tenofovir exposure, if feasible, either by substituting tenofovir alafenamide for tenofovir disoproxil fumarate, or rilpivirine, a weaker cytochrome P-450 3A4 inducer, or an integrase strand transfer inhibitor for efavirenz. Of note, despite significantly higher tenofovir levels when coadministered with efavirenz and ledipasvir in clinical trials, changes in creatinine clearance were similar to those in patients not taking antiretrovirals. ${ }^{21}$

As noted above, rilpivirine is generally more easily coadministered with most direct-acting antiviral regimens. No clinically significant interactions were identified with simeprevir, ledipasvir/sofosbuvir, elbasvir/grazoprevir or daclatasvir. However, rilpivirine administration with paritaprevir, ritonavir, ombitasvir and dasabuvir combination therapy resulted in 3.25-fold increase in rilpivirine exposure due to cytochrome 
Table 4. Summary of direct-acting antiviral regimen and antiretroviral regimen compatibility ${ }^{29-33}$

\begin{tabular}{|c|c|c|c|c|c|c|}
\hline $\begin{array}{l}\text { Preferred } \\
\text { Antiretroviral } \\
\text { Regimen }\end{array}$ & $\begin{array}{l}\text { Daclatasvir/ } \\
\text { Sofosbuvir* }\end{array}$ & $\begin{array}{l}\text { Grazoprevir/ } \\
\text { Elbasvir }\end{array}$ & $\begin{array}{l}\text { Ledipasvir/ } \\
\text { Sofosbuvir }\end{array}$ & $\begin{array}{l}\text { Paritaprevir/Ritonavir/ } \\
\text { Ombitasvir/Dasabuvir }\end{array}$ & $\begin{array}{l}\text { Simeprevir/ } \\
\text { Sofosbuvir }\end{array}$ & $\begin{array}{l}\text { Velpatasvir/ } \\
\text { Sofosbuvir }\end{array}$ \\
\hline $\begin{array}{l}\text { Dolutegravir/ } \\
\text { abacavir/lamivudine }\end{array}$ & Y & Y & Y & $\mathrm{Y}$ & Y & Y \\
\hline $\begin{array}{l}\text { Dolutegravir + } \\
\text { tenofovir disoproxil } \\
\text { fumarate/ } \\
\text { emtricitabine }\end{array}$ & Y & $\mathrm{Y}$ & Y & Y & Y & Y \\
\hline $\begin{array}{l}\text { Elvitegravir/ } \\
\text { cobicistat/tenofovir } \\
\text { disoproxil fumarate/ } \\
\text { emtricitabine }\end{array}$ & $\begin{array}{l}\text { Y, } \\
\text { daclatasvir } \\
30 \mathrm{mg}\end{array}$ & $\mathrm{N}$ & Y & $\mathrm{N}$ & $\mathrm{N}$ & $\mathrm{Y}^{* *}$ \\
\hline $\begin{array}{l}\text { Elvitegravir/ } \\
\text { cobicistat/tenofovir } \\
\text { alafenamide/ } \\
\text { emtricitabine }\end{array}$ & $\begin{array}{l}\text { Y, } \\
\text { daclatasvir } \\
30 \mathrm{mg}\end{array}$ & $\mathrm{N}$ & $\mathrm{N}$ & $\mathrm{N}$ & $\mathrm{N}$ & Y \\
\hline $\begin{array}{l}\text { Raltegravir + } \\
\text { tenofovir disoproxil } \\
\text { fumarate/ } \\
\text { emtricitabine }\end{array}$ & Y & Y & Y & $\mathrm{Y}$ & Y & Y \\
\hline $\begin{array}{l}\text { Darunavir/ritonavir + } \\
\text { tenofovir } \\
\text { DF/emtricitabine }\end{array}$ & Y & $\mathrm{N}$ & $\mathrm{Y}^{* *}$ & $\mathrm{~N}$ & $\mathrm{~N}$ & $\mathrm{Y}^{* *}$ \\
\hline \multicolumn{7}{|c|}{ Alternative antiretroviral regimen } \\
\hline $\begin{array}{l}\text { Atazanavir/cobicistat } \\
+ \text { tenofovir disoproxil } \\
\text { fumarate/ } \\
\text { emtricitabine }\end{array}$ & $\begin{array}{l}\text { Y, } \\
\text { daclatasvir } \\
30 \mathrm{mg}\end{array}$ & $\mathrm{N}$ & Y & $\mathrm{N}$ & $\mathrm{N}$ & $\mathrm{Y}^{* *}$ \\
\hline $\begin{array}{l}\text { Atazanavir }+ \\
\text { ritonavir }+ \text { tenofovir } \\
\text { disoproxil fumarate/ } \\
\text { emtricitabine }\end{array}$ & $\begin{array}{l}\text { Y, } \\
\text { daclatasvir } \\
30 \mathrm{mg}\end{array}$ & $\mathrm{N}$ & Y & $\mathrm{Y}^{* *}$ & $\mathrm{~N}$ & $\mathrm{Y}^{* *}$ \\
\hline $\begin{array}{l}\text { Darunavir/cobicistat } \\
\text { OR Darunavir + } \\
\text { ritonavir + abacavir/ } \\
\text { lamivudine }\end{array}$ & Y & $\mathrm{N}$ & Y & $\mathrm{N}$ & $\mathrm{N}$ & Y \\
\hline $\begin{array}{l}\text { Efavirenz/ tenofovir } \\
\text { disoproxil fumarate/ } \\
\text { emtricitabine }\end{array}$ & $\begin{array}{l}\text { Y, } \\
\text { daclatasvir } \\
90 \mathrm{mg}\end{array}$ & $\mathrm{N}$ & $\mathrm{Y}^{* *}$ & $\mathrm{~N}$ & $\mathrm{~N}$ & $\mathrm{~N}$ \\
\hline $\begin{array}{l}\text { Rilpivirine/tenofovir } \\
\text { alafenamide/ } \\
\text { emtricitabine }\end{array}$ & Y & $Y$ & Y & $\mathrm{N}$ & $Y$ & $Y$ \\
\hline $\begin{array}{l}\text { Rilpivirine/tenofovir } \\
\text { disoproxil fumarate/ } \\
\text { emtricitabine }\end{array}$ & $Y$ & $\mathrm{Y}$ & $Y$ & $\mathrm{~N}$ & $\mathrm{Y}$ & $\mathrm{Y}^{* *}$ \\
\hline
\end{tabular}

Antiretroviral regimens based on the recommendations of the United States Department of Health and Human Services. Y: Use at normal doses appropriate, N: Do not use concurrently. DHHS refers to the Department of Health and Human Services.

* Daclatasvir dose is $60 \mathrm{mg}$, unless otherwise noted, when able to be combined.

** Potential increase in tenofovir levels when using ledipasvir/sofosbuvir or velpatasvir/sofosbuvir concurrently with some tenofovir disoproxil fumarate containing regimens; monitor for renal adverse events. Interaction not expected with tenofovir alafenamide formulations.

*** Discontinue additional ritonavir when using paritaprevir, ritonavir, ombitasvir and dasabuvir combination therapy with atazanavir ritonavir, since it contains enough ritonavir to boost atazanavir. Resume extra ritonavir after hepatitis $\mathrm{C}$ virus therapy completed.

P-450 3A4 inhibition by ritonavir, risking increased toxicity (central nervous system, hepatotoxicity or Q-T prolongation). ${ }^{22}$ Paritaprevir concentrations are also increased when coadministered with rilpivirine. There is potential for a decrease in daclatasvir exposure when coadministered with etravirine, also a cytochrome P-450 3A4 inducer. ${ }^{1}$ Therefore, an increased dose of $90 \mathrm{mg}$ daclatasvir is recommended. Etravirine also reduces the concentrations of paritaprevir, 
ritonavir, ombitasvir and dasabuvir combination therapy components and, therefore, theoretically its efficacy, so it should not be coadministered. ${ }^{1}$ Similar interactions are expected with elbasvir/grazoprevir. ${ }^{22}$

\section{HIV PIs}

Ritonavir is a potent inhibitor of the cytochrome P-450 3A4 enzyme used to boost HIV PIs, and may also increase exposure to daclatasvir. Studies in healthy volunteers who were given ritonavir-boosted atazanavir showed 2.1-fold increased area under the curve (AUC) of daclatasvir, indicating that daclatasvir dosing should be reduced to $30 \mathrm{mg}$ when given with ritonavir-boosted atazanavir. Similar interactions were predicted with ritonavir-boosted darunavir and lopinavir. ${ }^{22}$ However, patients taking ritonavir-boosted darunavir and a reduced dose of $30 \mathrm{mg}$ daclatasvir had lower rates of sustained virologic response at 12 weeks after completion of therapy $(67 \%)$, suggesting insufficient dosing of daclatasvir. ${ }^{23}$ A subsequent study of daclatasvir with ritonavir-boosted darunavir and lopinavir showed only moderate increases in daclatasvir $\mathrm{AUC}_{1}{ }^{24}$ in contrast to atazanavir/ritonavir, and follow-up data yielded a sustained virologic response at 12 weeks after completion of therapy for $93 \%$ of the patients receiving $30 \mathrm{mg}$ daclatasvir with boosted darunavir or lopinavir/ritonavir. ${ }^{25}$ Daclatasvir dose adjustment is not currently recommended in the setting of ritonavir-boosted darunavir or lopinavir administration.

Patients receiving ritonavir-boosted atazanavir for their HIV can safely be given paritaprevir, ritonavir, ombitasvir and dasabuvir combination therapy; however, care must be taken not to exceed the recommended ritonavir dosing. Because paritaprevir and ombitasvir are only available in a fixed-dose combination with ritonavir, the ritonavir administered as part of the antiretroviral regimen should be held for the duration of therapy. ${ }^{1}$ It is also necessary to administer atazanavir at the same time due to the short half-life of ritonavir. Lopinavir is given as a twice-daily dose boosted with ritonavir, and coadministration with paritaprevir, ritonavir, ombitasvir and dasabuvir combination therapy would yield a total daily ritonavir dose of $300 \mathrm{mg}$, which is likely to cause gastrointestinal adverse effects. However, in pharmacokinetic studies of healthy volunteers, coadministration with lopinavir/ ritonavir did not result in any treatment discontinuations due to adverse events; although, isolated elevations in hepatic transaminases and bilirubin were noted. ${ }^{26}$ Paritaprevir exposure is increased with once-daily darunavir but decreased with twice-daily darunavir, for unclear reasons. Furthermore, darunavir trough levels are reduced when coadministered with paritaprevir, ritonavir, ombitasvir and dasabuvir combination therapy. Therefore, combining paritaprevir, ritonavir, ombitasvir and dasabuvir combination therapy with darunavir is not currently recommended. ${ }^{1}$ Simeprevir is also metabolized by the cytochrome P-450 3A4 enzyme and simeprevir exposure is markedly increased when given with a ritonavirboosted HIV PI. ${ }^{27}$

Patients taking tipranavir should not be given a regimen containing sofosbuvir, due to induction of the permeability glycoprotein system and decreased clearance of sofosbuvir. ${ }^{28}$

\section{Integrase strand transfer inhibitors}

Few drug-drug interactions have been reported for the integrase strand transfer inhibitors. There are no reported interactions between dolutegravir and daclatasvir, elbasvir/ grazoprevir, sofosbuvir either alone or in combination with ledipasvir, or with paritaprevir, ritonavir, ombitasvir and dasabuvir combination therapy. ${ }^{1}$ Increased serum concentrations of raltegravir have been noted when coadministered with paritaprevir, ritonavir, ombitasvir and dasabuvir combination therapy. ${ }^{22}$ However, this increase is not likely to be clinically significant. The AUC remains within acceptable limits, given that raltegravir has a wide safety margin. ${ }^{8}$ Coadministration of raltegravir with ledipasvir decreases serum concentration of raltegravir by approximately $27 \%$, and patients on this combination should be monitored closely for HIV viral breakthrough. ${ }^{22}$ Raltegravir has been safely administered with daclatasvir, elbasvir/grazoprevir, sofosbuvir, ledipasvir and simeprevir. $^{1,22}$

The use of cobicistat-boosted integrase strand transfer inhibitors, specifically elvitegravir (currently available only in a fixed-dose combination), is not recommended for use with simeprevir or ledipasvir. Cobicistat is a cytochrome P-450 3A4 inducer and is theorized to increase simeprevir levels. ${ }^{4}$ It is expected that simeprevir levels would be elevated similar to that seen when coadministered with ritonavir, though this has not been studied directly. ${ }^{22}$ Cobicistat-boosted elvitegravir, when used with tenofovir disoproxil fumarate, should not be combined with ledipasvir as this can potentially raise tenofovir concentration to toxic levels. ${ }^{4}$ The use of tenofovir alafenamide may be considered.

Daclatasvir administered with sofosbuvir is regarded as a safer combination with elvitegravir/cobicistat. Although it also undergoes metabolism by cytochrome P-450 3A4, daclatasvir dose can be reduced from $60 \mathrm{mg}$ to $30 \mathrm{mg}$ when used with a cobicistat-boosted regimen to account for this change. ${ }^{4,22}$ Elbasvir/grazoprevir is also not recommended for use with cobicistat given the potential for drug-drug interactions mediated by the cytochrome P-450 3A4 induction.

\section{Entry inhibitors}

Maraviroc and enfuvirtide are entry inhibitors that are used infrequently for deep salvage antiretroviral therapy in patients with high treatment experience. There is little data available with regard to drug-drug interactions at this time. Clinically significant interactions are not suspected between maraviroc and daclatasvir, sofosbuvir or simeprevir based on the pharmacokinetic information available. ${ }^{22,23}$

\section{Pangenotypic regimens}

Velpatasvir is newly approved by the United States Food and Drug Administration and functions as an HCV non-structural protein $5 \mathrm{a}$ inhibitor, exerting potent pangenotypic antiviral activity against genotypes 1 through $6 .{ }^{12-14}$ Phase I clinical trials have analyzed drug-drug interactions with select antiretrovirals, including efavirenz, rilpivirine, raltegravir, dolutegravir, elvitegravir/cobicistat, atazanavir/ritonavir, darunavir/ ritonavir, lopinavir/ritonavir, tenofovir disoproxil fumarate and tenofovir alafenamide. ${ }^{15}$ No clinically meaningful interactions have been observed with most of the antiretrovirals. Because velpatasvir is a substrate of the permeability glycoprotein and cytochrome P-450 3A4, administration with potent cytochrome P-450 inducers, such as efavirenz, is not recommended. ${ }^{15}$ As with ledipasvir, close monitoring of renal function for tenofovir-associated toxicity is indicated when 
velpatasvir is coadministered with tenofovir disoproxil fumarate, less so with tenofovir alafenamide.

\section{Conclusions}

Eradication of chronic HCV infection in patients coinfected with HIV should be a priority for providers who care for these patients in order to reduce significant long-term morbidity and mortality attributable to liver disease. Making antiretroviral switches in order to accommodate direct-acting antiviral therapy, however, must be undertaken with precision and careful consideration. In the absence of a clearly superior regimen for treatment of $\mathrm{HCV}$, we have herein described interactions with antiretroviral agents to facilitate the selection of an appropriate individualized regimen. Ongoing innovations in testing and drug development are necessary to further streamline and simplify the management of these patients.

\section{Conflict of interest}

Dr. Faragon has disclosed that he has received honoraria from AbbVie, BMS, Gilead, Merck, and Viiv.

\section{Author contributions}

Conception and design of this work (DR, LC), review of pertinent literature and drafting of the article (DR, JF, SB, $\mathrm{LC})$, critical revision of the article (DR), final review and approval of the version to be published (DR, JF, SB, LC).

\section{References}

[1] HCV guidance: Recommendations for testing, managing, and treating hepatitis C. Available from: http://www.hcvguidelines.org, accessed June 2016.

[2] Kirk GD, Mehta SH, Astemborski J, Galai N, Washington J, Higgins Y, et al. HIV, age, and the severity of hepatitis C virus-related liver disease: a cohort study. Ann Intern Med 2013;158:658-666. doi: 10.7326/0003-4819-158-9201305070-00604.

[3] Viral hepatitis-Hepatitis C. information. Available from: http://www.cdc. gov/hepatitis/hcv/statisticshcv.htm, accessed June 2016.

[4] Cope R, Pickering A, Glowa T, Faulds S, Veldkamp P, Prasad R. Majority of $\mathrm{HIV} / \mathrm{HCV}$ patients need to switch antiretroviral therapy to accommodate direct acting antivirals. AIDS Patient Care and STDS 2015;29:379-383. doi: 10.1089/apc.2015.0004.

[5] GenoSure Archive ${ }^{\circledR}$. Available from: http://www.monogrambio.com/hivtests/suppression-management/genosure-archive, accessed June 2016.

[6] van der Meer AJ, Veldt BJ, Feld JJ, Wedemeyer H, Dufour JF, Lammert F, et al. Association between sustained virological response and all-cause mortality among patients with chronic hepatitis $\mathrm{C}$ and advanced hepatic fibrosis. JAMA 2012;308:2584-2593. doi: 10.1001/jama.2012.144878.

[7] ZEPATIER ${ }^{\text {TM }}$. Available from: http://www.merck.com/product/usa/pi_circulars/z/zepatier/zepatier_pi.pdf, accessed July 2016.

[8] Khatri A, Dutta S, Dunbar M, Podsadecki T, Trinh R, Awni W, et al. Evaluation of drug-drug interactions between direct-acting anti-hepatitis $C$ virus combination regimens and the HIV-1 antiretroviral agents raltegravir, tenofovir, emtricitabine, efavirenz, and rilpivirine. Antimicrob Agents Chemother 2016;60:2965-2971. doi: 10.1128/AAC.02605-15.

[9] EPCLUSA. Available from: http://www.gilead.com/ /media/Files/pdfs/medicines/liver-disease/epclusa/epclusa_pi.pdf, accessed June 2016.

[10] Ruane P, Adeyemi O, Trinh R, Lalezari J, Bhatti L, Slim J, et al. TURQUOISE-I study: use of ombitasvir/paritaprevir/ritonavir + dasabuvir + ribavirin in patients with HCV/HIV-1 co-infection on stable darunavir-containing antiretroviral therapy [Abstract LBPS7/1]. 15 ${ }^{\text {th }}$ European AIDS Clinical Society Conference; 2015 Oct 21-24; Barcelona, Spain.

[11] German P, Garrison K, Pang PS, Stamm LM, Ray AS, Shen G, et al. Drugdrug interactions between anti-HCV regimen ledipasvir/sofosbuvir and antiretrovirals [Abstract 82]. 22 ${ }^{\text {nd }}$ Conference on Retroviruses and Opportunistic Infections; 2015 Feb 23-26; Seattle, WA.
[12] German P, Pang PS, West S, Han L, Sajwani K, Mathias A. Drug interactions between direct adting anti-HCV antivirals sofosbuvir and ledipasvir and HIV antiretrovirals [Abstract 06]. 15 ${ }^{\text {th }}$ International Workshop on Clinical Pharmacology of HIV and Hepatitis Therapy; 2014 May 19-21; Washington, DC.

[13] Garrison K, Custodio JM, Pang PS. Drug-interactions between anti-HCV antivirals ledipasvir/sofosbuvir and integrase strand transfer inhibitor-based regimens [Abstract 71]. $16^{\text {th }}$ International Workshop on Clinical Pharmacology of HIV and Hepatitis Therapy; 2015 May 26-28; Washington, DC.

[14] Bifano M, Hwang C, Oosterhuis B, Hartstra J, Grasela D, Tiessen R, et al. Assessment of pharmacokinetic interactions of the HCV NS5A replication complex inhibitor daclatasvir with antiretroviral agents: ritonavir-boosted atazanavir, efavirenz, and tenofovir. Antivir Ther 2013;18:931-940. doi: 10.3851/IMP2674.

[15] Kirby B, Mathias A, Rossi S, Moyer C, Shen G, Kearney BP. No clinically significant pharmacokinetic interactions between sofosbuvir (GS-7977) and HIV antiretrovirals atripla, rilpivirine, darunavir/ritonavir, or raltegravir in healthy volunteers. Hepatology 2012;56(suppl):1067A.

[16] Rockstroh JK, Nelson M, Katlama C, Lalezari J, Mallolas J, Bloch M, et al. Efficacy and safety of grazoprevir (MK-5172) and elbasvir (MK-8742) in patients with hepatitis $\mathrm{C}$ virus and HIV co-infection (C-EDGE CO-INFECTION): a non-randomized, open-label trial. Lancet HIV 2015;2:e319-e327. doi: 10. 1016/S2352-3018(15)00114-9.

[17] Khatri A, Wang T, Wang H, Podsadecki T, Trinh R, Awni W. Drug-drug interactions of the direct acting antiviral regimen of ABT-450/r, ombitasvir, and dasabuvir with emtricitabine + tenofovir, raltegravir, rilpivirine, and efavirenz [Abstract 483]. 54 ${ }^{\text {th }}$ Interscience Conference on Antimicrobial Agents and Chemotherapy; 2014 Sep 5-9; Washington, DC.

[18] Fleischer R, Boxwell D, Sherman KE. Nucleoside analogues and mitochondrial toxicity. Clin Infect Dis 2004;38:e79-e80. doi: 10.1086/383151.

[19] Alvarez D, Dieterich DT, Brau N, Moorehead L, Ball L, Sulkowski MS. Zidovudine use but not weight-based ribavirin dosing impacts anaemia during HCV treatment in HIV-infected persons. J Viral Hepat 2006;13:683-689. doi: 10. 1111/j.1365-2893.2006.00749.x.

[20] Esposito I, Labarga P, Barreiro P, Fernandez-Montero JV, de Mendoza C, Benítez-Gutiérrez L, et al. Dual antiviral therapy for HIV and hepatitis C drug interactions and side effects. Expert Opin Drug Saf 2015;14:14211434. doi: $10.1517 / 14740338.2015 .1073258$.

[21] Osinusi A, Townsend K, Kohli A, Nelson A, Seamon C, Meissner EG, et al. Virologic response following combined ledipasvir and sofosbuvir administration in patients with HCV genotype 1 and HIV co-infection. JAMA 2015;313: 1232-1239. doi: 10.1001/jama.2015.1373.

[22] El-Sherif O, Khoo S, Solas C. Key drug-drug interactions with direct-acting antiviral in HIV-HCV coinfection. Curr Opin HIV AIDS 2015;10:348-354. doi: $10.1097 / \mathrm{COH} .0000000000000185$.

[23] Wyles DL, Ruane PJ, Sulkowski MS, Dieterich D, Luetkemeyer A, Morgan TR, et al. Daclatasvir plus sofosbuvir for HCV in patients coinfected with HIV-1. N Engl J Med 2015;373:714-725. doi: 10.1056/NEJMoa1503153.

[24] Ghandhi $Y$, Adamczyk R, Wang R. Assessment of drug-drug interactions between daclatasvir and darunavir/ritonavir or lopinavir/ritonavir [Abstract $80] .16^{\text {th }}$ International Workshop on Clinical Pharmacology of HIV and Hepatitis Therapy; 2015 May 26-28; Washington, DC.

[25] Luetkemeyer AF, McDonald C, Ramgopal M, Noviello S, Bhore R, Ackerman P. 12 weeks of daclatasvir in combination with sofosbuvir for HIV-HCV coinfection (ALLY-2 study): efficacy and safety by HIV combination antiretroviral regimens. Clin Infect Dis 2016;62:1489-1496. doi: 10.1093/cid/ciw163.

[26] Khatri A, Dutta S, Wang H, Podsadecki T, Trinh R, Awni W, et al. Evaluation of drug-drug interactions between hepatitis $C$ antiviral agents ombitasvir, paritaprevir/ritonavir, and dasabuvir and HIV-1 protease inhibitors. Clin Infect Dis 2016;62:972-979. doi: 10.1093/cid/civ1213.

[27] Kiser J], Burton JR Jr, Everson GT. Drug-drug interactions during antiviral therapy for chronic hepatitis C. Nat Rev Gastroenterol Hepatol 2013;10:596606. doi: $10.1038 /$ nrgastro.2013.106.

[28] Sovaldi ${ }^{\circledR}$. Available from: http://www.gilead.com/ /media/Files/pdfs/medicines/liver-disease/sovaldi/sovaldi_pi.pdf, accessed July 2016.

[29] Daklinza ${ }^{\mathrm{TM}}$. Available from: http://packageinserts.bms.com/pi/pi_daklinza. pdf, accessed July 2016.

[30] Zepatier ${ }^{\mathrm{TM}}$. Available from: http://www.merck.com/product/usa/pi_circulars/z/zepatier/zepatier_pi.pdf, accessed July 2016.

[31] Harvoni ${ }^{\circledR}$. Available from: http://www.gilead.com/ /media/Files/pdfs/medicines/liver-disease/harvoni/harvoni_pi.pdf, accessed July 2016.

[32] Viekira pak. Available from: http://www.accessdata.fda.gov/drugsatfda docs/label/2014/206619lbl.pdf, accessed July 2016.

[33] Olysio capsules. Available from: http://www.olysio.com/shared/product/ olysio/prescribing-information.pdf, accessed July 2016

[34] Guidelines for the use of antiretroviral agents in HIV-1-infected adults and adolescents. Available from: http://aidsinfo.nih.gov/contentfiles/lvguidelines/adultandadolescentgl.pdf, accessed July 2016. 